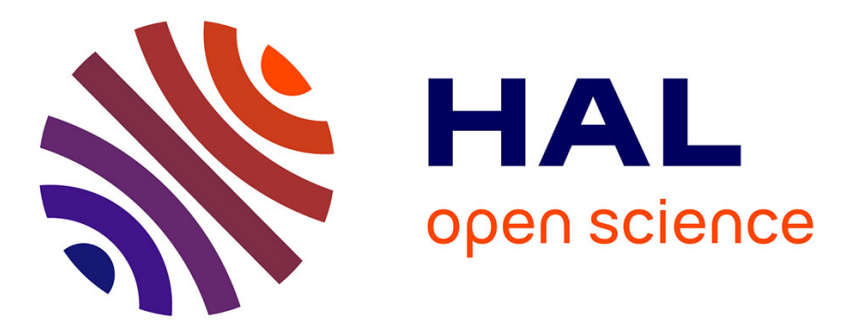

\title{
Bidirectional modulation of windup by NMDA receptors in the rat spinal trigeminal nucleus
}

Alain Woda, Olivier Blanc, Daniel L. Voisin, Jerome Coste, Jean-Louis Molat, Philippe Luccarini

\section{- To cite this version:}

Alain Woda, Olivier Blanc, Daniel L. Voisin, Jerome Coste, Jean-Louis Molat, et al.. Bidirectional modulation of windup by NMDA receptors in the rat spinal trigeminal nucleus. European Journal of Neuroscience, 2004, 19 (8), pp.2009-2016. 10.1111/j.0953-816X.2004.03328.x · hal-01543022

\section{HAL Id: hal-01543022 \\ https://hal.science/hal-01543022}

Submitted on 22 Jun 2017

HAL is a multi-disciplinary open access archive for the deposit and dissemination of scientific research documents, whether they are published or not. The documents may come from teaching and research institutions in France or abroad, or from public or private research centers.
L'archive ouverte pluridisciplinaire HAL, est destinée au dépôt et à la diffusion de documents scientifiques de niveau recherche, publiés ou non, émanant des établissements d'enseignement et de recherche français ou étrangers, des laboratoires publics ou privés. 


\title{
Bidirectional modulation of windup by NMDA receptors in the rat spinal trigeminal nucleus
}

\author{
A Woda, O Blanc, DL Voisin, J Coste; J-L Molat; P Luccarini \\ Inserm E216 Neurobiologie de la Douleur Trigéminale, Faculté de chirurgie dentaire, 11 \\ boulevard Charles de Gaulle, 63000 Clermont-Ferrand, France
}

\section{Corresponding author:}

Daniel L Voisin

Email: daniel.voisin@u-clermont1.fr

Running head: NMDA dependent inhibition of windup

Keywords: nociception, pain, subnucleus oralis, Sprague-Dawley rat, wide dynamic range 


\section{Abstract}

Activation of afferent nociceptive pathways is subject to activity-dependent plasticity, which may manifest as windup, a progressive increase in the response of dorsal horn nociceptive neurons to repeated stimuli. At the cellular level, $\mathrm{N}$-methyl- D -aspartate (NMDA) receptor activation by glutamate released from nociceptive $\mathrm{C}$-afferent terminals is currently thought to generate windup. Most of the wide dynamic range nociceptive neurons that display windup, however, do not receive direct $\mathrm{C}$-fibre input. It is thus unknown where the NMDA mechanisms for windup operate. Here, using the Sprague-Dawley rat trigeminal system as a model, we anatomically identify a subpopulation of interneurons that relay nociceptive information from the superficial dorsal horn where $\mathrm{C}$-fibres terminate, to downstream wide dynamic range nociceptive neurons. Using in vivo electrophysiological recordings, we show that at the end of this pathway, windup wasreduced $(24+/-6 \%, \mathrm{n}=7)$ by the NMDA receptor antagonist AP-5 $(2.0 \mathrm{fmol})$ and enhanced $(62+/-19 \%, \mathrm{n}=12)$ by NMDA $(1 \mathrm{nmol})$. In contrast, microinjections of AP-5 (1.0fmol) within the superficial laminae increased windup $(83+/-44 \%, \mathrm{n}=9)$, whereas NMDA dose dependently decreased windup ( $\mathrm{n}=19)$. These results indicate that NMDA receptor function at the segmental level depends on their precise location in nociceptive neural networks. While some NMDA receptors actually amplify pain information, the new evidence for NMDA dependent inhibition of windup we show here indicates that, simultaneously, others act in the opposite direction. Working together, the two mechanisms may provide a fine tuning of gain in pain. 


\section{Introduction}

In the spinal dorsal horn and brainstem trigeminal system, a simple form of activity-dependent plasticity is windup, in which repetitive stimulation of peripheral nociceptive $\mathrm{C}$-fibres induces a progressive increase in the response of central nociceptive neurons (Mendell \& Wall, 1965). indup therefore amplifies the nociceptive message (Baranauskas \& Nistri, 1998; Herrero et al., 2000; Woolf \& Salter, 2000). As such, windup plays a part in the continuum encompassing the diverse reactions of nociceptive neurons to changes in their activity or environment (Woolf \& Salter, 2000). Understanding the mechanisms responsible for windup would help to elucidate an important feature of pain signalling (Woolf, 1996; Woolf et al., 1998).

At the cellular level, windup is currently thought to result from both intrinsic and synaptic mechanisms (Woolf \& Salter, 2000). The intrinsic neuronal ability to generate windup relies on the recruitment of voltage-gated currents triggering plateau-potentials (Morisset \& Nagy, 1999; Russo \& Hounsgaard, 1999; Morisset \& Nagy, 2000; Derjean et al., 2003). Synaptic activation of glutamate (NMDA) and neurokinin receptors by glutamate and substance $\mathrm{P}$, released from primary C-afferent terminals, is also believed to be critically involved in windup (Urban et al., 1994; Baranauskas \& Nistri, 1998; Herrero et al., 2000). Most wide dynamic range (WDR) nociceptive cells that trongly windup their response to C-fibre activation, however, are located in the deep dorsal horns of the spinal cord (Schouenborg \& Sjölund, 1983). Windup is present only in some superficial dorsal hornneurons (Schouenborg \& Sjölund, 1983; Jeftinija \& Urban, 1994; Yoshimura, 1996). As cutaneous C-fibres terminate in the superficial laminae of the dorsal horn only, the deep dorsal horn WDR nociceptive cells do not therefore receive direct C-fibre input (Light \& Perl, 1979a; Light \& Perl, 1979b; Ralston, III \& Ralston, 1982; Sugiura et al., 1986). It is thus unknown where the synaptic mechanisms for windup operate. In the present work, we sought to understand where and how NMDA receptors are involved in windup.

In the spinal dorsal horn, the C-fibre mediated nociceptive information is brought from the superficial laminae to the deep ones through local interneurons (Ritz \& Greenspan, 1985; Light \& Kavookjian, 1988; Li et al., 1999; Nakatsuka et al., 2002). The NMDA mechanisms for WDR nociceptive neuron windup may thus operate at either end of these interneurons. The close proximity of the laminae in the spinal dorsal horn, however, makes it extremely difficult to microinject drugs in the superficial laminae without having a direct effect on nociceptive neurons recorded from deeper laminae. To overcome this problem, we used the rat spinal trigeminal 
nucleus in which a pool of WDR neurons is located rostrally, in the subnucleus oralis (Sp5O), approximately $3 \mathrm{~mm}$ apart from C-fibre afferent terminals that abut caudally, in the superficial laminae of the medullary dorsal horn (MDH; Dallel et al., 1990; Dallel et al., 1998; Dallel et al., 1999; Sessle, 2000). First, we found that, similar to that which exists in the spinal dorsal horn, interneurons relay nociceptive information from the superficial laminae of the MDH to downstream WDR trigeminal neurons. This confirmed the validity of the trigeminal model. We then examined where and how NMDA receptor-dependent mechanisms for windup operate. 


\section{Material and methods}

Adult male Sprague-Dawley rats (280-300 g) were obtained from Iffa Credo (France) and maintained in a controlled environment (lights on 07:00-21:00 h, 22 ${ }^{\circ} \mathrm{C}$ ) with food and water freely available. All efforts were made to minimize the number of animals used. The experiments followed the ethical guidelines of the International Association for the Study of Pain and the European communities Council directive of 24 November 1986 (86/609/EEC).

\section{Retrograde tracing and Fos immunocytochemistry}

Animals were anaesthetized with chloral hydrate $(400 \mathrm{mg} / \mathrm{kg}$, i.p. injected) and placed in a stereotaxic frame. Through a craniotomy, a glass micropipette containing retrograde fluorescent tracer fluorogold (Molecular Probes, Eugene, OR, USA) was inserted stereotaxically so that its tip (25-40 $\mu \mathrm{m}$ diameter) was located within the dorsal portion of the ventrolateral part of the right Sp5O (AP -1.8 to -2.3, ML 3.0, P 9.0 according to Paxinos \& Watson, 1997). Fluorogold was injected electrophoretically (positive current, $5 \mu \mathrm{A}, 10-15 \mathrm{~min}$ ). Two days later, rats were anaesthetized with urethane $(1.1 \mathrm{~g} / \mathrm{kg}$, i.p) and injected with $100 \mu \mathrm{L} 0.1 \%$ capsaicin in the right upper lip. Two hours later they were perfused intracardially with heparinized saline followed by paraformaldehyde $(4 \%)$ and picric acid $(0.8 \%)$ in phosphate buffer. Brainstems were removed and left overnight in fixative containing $30 \%$ sucrose at $4^{\circ} \mathrm{C}$. Coronal sections $(30 \mu \mathrm{m}$ thickness) were cut on a freezing microtome. Sections underwent free- oating dual immunostaining using first a rabbit antibody specific for uorogold (1 : 5000,48 h; Chemicon, Temecula, CA, USA), followed by a Fos antibody (c-fos Ab-2, 1 : 1000, 48 h; Oncogene Research Products, Cambridge, MA, USA). Immunoreactivity for uorogold was visualized using diaminobenzidine tetrahydrochloride (DAB) while Fos-like immunoreactivity was detected with a nickel-enhanced DAB procedure. Controls consisted of the omission of the primary antibody and incubation of sections in inappropriate secondary antibodies. In all these control experiments, no specific staining was evident. Computer-assisted bright-field images of representative labelling and Foslike immunoreactivity were obtained using a CCD colour video camera (Sony DXC-950P) connected to a Nikon Optiphot-2 microscope sending an RGB output to a PC microcomputer. Images were captured and digitized using the Vision Stage and Neurolab 2.02 software (Alliance Vision, Mirmande, France; Voisin et al., 2002). Representations of the sites of injection were grouped on standard drawings of the Sp5O. Retrogradely labelled cell bodies expressing Fos- 
positive nuclei were counted according to their laminar location along different rostrocaudal planes within the MDH. One single tissue section was counted for each level in each animal. Brainstem sections were categorized according to their approximate rostrocaudal location at $360 \mu \mathrm{m}$ intervals from $+720 \mu \mathrm{m}$ to $-3240 \mu \mathrm{m}$ relative to the most caudal tip of the spinal trigeminal nucleus subnucleus interpolaris/MDH transition region as described by Yoshida et al. (1991). The rostral level of the range $(720 \mu \mathrm{m})$ corresponded to the end of the transition level. The spinomedullary junction was considered to be at $-2160 \mu \mathrm{m}$ (approximately the caudal end of the pyramidal decussation) and the $\mathrm{C} 1-\mathrm{C} 2$ junction, which corresponded to the end of the range, at $3240 \mu \mathrm{m}$. The delineation of the different laminae of the MDH was adapted from Strassman \& Vos (1993). Representative examples of the distribution of retrogradely labelled cell bodies were grouped on standard drawings of the MDH.

\section{Electrophysiology}

Rats were anaesthetized with $2 \%$ halothane in a nitrous oxide : oxygen mixture $(2: 3,1: 3)$. After intraperitoneal injection of $100 \mu \mathrm{g}$ atropine sulphate, a tracheal cannula was inserted and the jugular vein cannulated. Rats were paralysed by a perfusion of pancuronium bromide $(0.5 \mathrm{mg} / \mathrm{h})$ and artificially ventilated with a volume-controlled pump. They were placed in a stereotaxic frame and a craniotomy and $\mathrm{C} 1$ laminectomy performed to give access to the $\mathrm{Sp} 5 \mathrm{O}$ and the $\mathrm{MDH}$, respectively. After surgery, the levels of halothane $(0.5 \%), \mathrm{O}_{2}, \mathrm{~N}_{2} \mathrm{O}$ and end-tidal $\mathrm{CO}_{2}$ (3.5-4.5\%) were monitored together with heart rate and core temperature, under the control of alarms (Dallel et al., 1990; Dallel et al., 1998; Dallel et al., 1999). This anaesthetic regime gives a stable level of anaesthesia sufficient to avoid suffering during the application of noxious stimuli (Dallel et al., 1988).

Unitary extracellular recordings were made using single or double/triple barrel glass pipettes made according to a method adapted from Akaoka et al . (1992). The recording pipette (7-10 $\mathrm{MOhm}$ ) was filled with a mixture of $5 \% \mathrm{NaCl}$ and pontamine sky blue. Single unit activities were amplified and displayed on oscilloscopes, and also led into a window discriminator connected to a CED 1401plus interface and a computer (CED and Spike 2.01 software; Cambridge Electronic Design, UK) to allow sampling and analysis of neuronal activity.

Neurons were classified as WDR on the basis of their responses to both mechanical and percutaneous electrical stimulation applied to their receptive field (Dallel et al., 1990; Dallel et 
al., 1998). Innocuous mechanical stimuli to the skin, mucosa and teeth included air puffs, brushing with a soft brush, gentle stroking and light pressure with a blunt probe. Noxious mechanical timuli consisted of heavy pressure, pinprick and pinching with fine forceps (tip area 1 $\mathrm{mm}^{2}$ ) which evoked a painful sensation when applied to the experimenters' skin. Once a neuron had been identified, the extent of its receptive field was determined and mapped and its location was designated in terms of its involvement in intraoral, perioral or more peripheral regions of the face (Dallel et al., 1990). Electrical square-wave stimuli (2 ms duration) were applied through a pair of stainless steel stimulating electrodes inserted subcutaneously into the centre of the previously delineated receptive field. The thresholds for obtaining A-fibre and C-fibre responses were determined. Increasing the current to a suprathreshold value induced reproducible responses. Post-stimulus histograms were analysed to distinguish responses due to A-fibre and Cfibre inputs, according to their latencies and by using the classification of Gasser \& Erlanger (1927) and Burgess \& Perl (1973).

All drugs were purchased from Sigma. They were microinjected into the $\mathrm{Sp5O}$ by air pressure (5$10 \mathrm{~nL}$ for $50 \mathrm{~ms}$ ), using ejection pipettes stuck to the recording pipette, and into the MDH through micropipettes $(0.25 \mu \mathrm{L}$ for $2 \mathrm{~min})$ connected to Hamilton syringes (Dallel et al., 1998). Sequences of 30 electrical stimulations $(0.66 \mathrm{~Hz}, 1.5-3$-fold C-fibre threshold intensity) were delivered every 5 min until two successive trials displayed less than $10 \%$ variation in responses, which served as control. Windup was calculated as the difference between the total number of action potentials evoked by the 30 stimuli at $\mathrm{C}$-fibre latencies and the number of action potentials produced by the first stimulus multiplied by 30 (Chapman et al., 1994; Dallel et al., 1999). Results are expressed as mean+/-SEM. Statistical analysis used t-test, one way ANOVA or Friedman repeated measures ANOVA on ranks followed by appropriate posthoc tests (Tukey or Dunnet). The level of significance was set at $\mathrm{P}<0.05$.

At the end of the experiment, injection of pontamine sky blue allowed further histological delineation of the recording and injection sites. The animal was killed by injection of a lethal dose of pentobarbital, its brainstem removed and fixed by immersion in a $10 \%$ formaldehyde solution. 


\section{Results}

\section{Intratrigeminal connections relay $\mathrm{C}$-fibre input from the $\mathrm{MDH}$ to the $\mathrm{Sp5O}$}

To chart the pathway bringing C-fibre mediated nociceptive information from the MDH to the $\mathrm{Sp5O}$, we combined neuroanatomical retrograde tracing from the Sp5O with Fos expression upon nociceptive stimulation (Hunt et al., 1987; Strassman \& Vos, 1993). Injection of capsaicin, a selective activator of C-fibre nociceptors (Caterina \&Julius, 2001), in the upper lip resulted in strong, somatotopic Fos expression in laminae I-II of the MDH ( $\mathrm{n}=5$ rats, Table 1, Fig. 1C). Injections of the retrograde tracer uorogold were performed in the somatotopically corresponding portion of the $\mathrm{Sp5O}$ (Voisin et al., 2002; n =8 rats; Fig. 1A). Cell bodies labelled retrogradely were found in lamina I, external II and to a greater degree in laminae III-IVand V of the ipsilateral, rostral MDH (Table 1; Fig. 1B). The internal lamina II was almost devoid of labelling. Double labelled neurons were found in lamina I and external II, at rostral levels $(n=5$ rats; Table 1, Fig. 1D and E). No colocalization was found in the three unstimulated rats. These data provided an anatomical support for C-fibre activation of Sp5O WDR neurons via a subpopulation of interneurons whose cell bodies are located in the superficial laminae of the MDH. The synaptic mechanisms for Sp5O neuron windup may thus operate at either end of these interneurons.

Table 1. Rostrocaudal and lamina-specific distribution of fos-like immunoreactivity and retrograde labelling in the medullary dorsal horn of stimulated animals

\begin{tabular}{|c|c|c|c|c|c|}
\hline & $\begin{array}{l}\text { Number of } \\
\text { Fos-positive } \\
\text { nuclei }\end{array}$ & $\begin{array}{l}\text { Number of neurons } \\
\text { retrogradely labelled } \\
\text { in laminae I-II }\end{array}$ & $\begin{array}{l}\text { Percentage of double } \\
\text { (vs. retrogradely) labelled } \\
\text { neurons in laminae I-II }\end{array}$ & $\begin{array}{l}\text { Number of neurons } \\
\text { retrogradely labelled } \\
\text { in laminae III-IV }\end{array}$ & $\begin{array}{l}\text { Number of neurons } \\
\text { retrogradely labelled } \\
\text { in lamina V }\end{array}$ \\
\hline MDH-interpolaris & $26 \pm 15$ & $13 \pm 3$ & $11 \pm 4 \%$ & $100 \pm 18$ & $52 \pm 11$ \\
\hline Rostral MDH & $51 \pm 18$ & $10 \pm 2$ & $26 \pm 4 \%$ & $65 \pm 7$ & $33 \pm 6$ \\
\hline Caudal MDH & $19 \pm 9$ & $2 \pm 1$ & $15 \pm 10 \%$ & $23 \pm 6$ & $9 \pm 3$ \\
\hline $\mathrm{Cl}$ & $10 \pm 5$ & $3 \pm 1$ & $0 \pm 0 \%$ & $16 \pm 6$ & $6 \pm 1$ \\
\hline
\end{tabular}

Data are presented as means per slice+/-SEM, $n=5$ rats. 


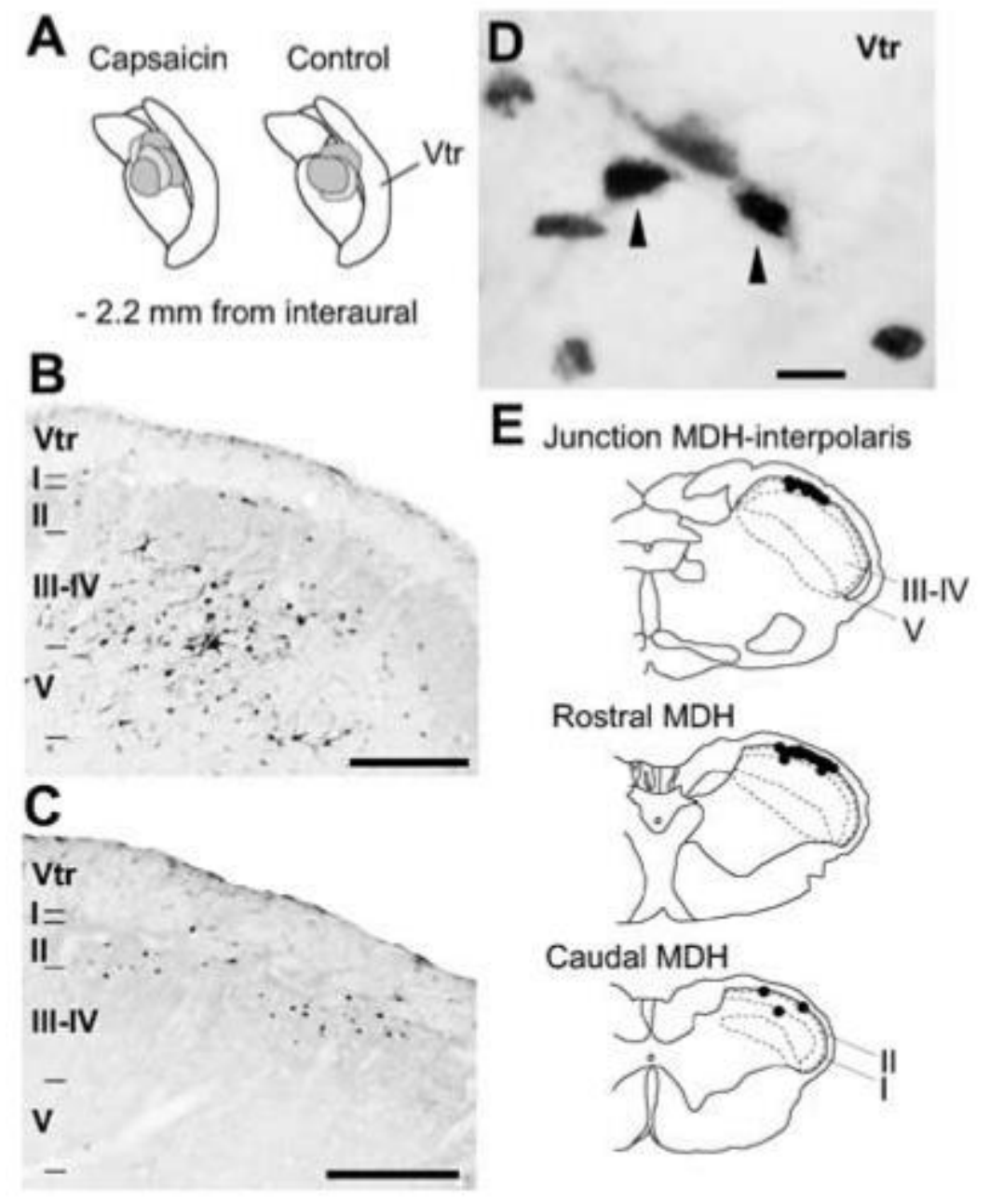

Fig.1. Intratrigeminal connections relay $C$-fibre input from the superficial laminae of the MDH to the Sp5O. (A) Camera lucida diagrams representing the coronal level at which the retrograde tracer fuoorogold deposition was maximal in the Sp5O. (B) Low-power view of retrogradely labelled neurons in the rostral MDH. (C) Image of Fos-immunoreactive cell nuclei in the rostral $\mathrm{MDH}$ following capsaicin injection in the upper lip (different animal from B). (D) High-power views of retrogradely labelled neurons expressing Fos-immunoreactive nuclei (arrowheads). (E) Drawings showing the distribution of retrogradely labelled neurons expressing Fosimmunoreactive nuclei at different rostro-caudal levels of the $M D H$ in five animals. $I-V$, laminae

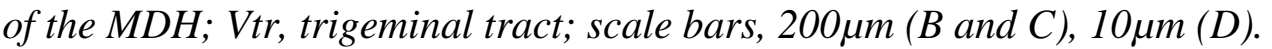

\section{Sp50 WDR nociceptive neurons display windup}

As NMDA receptors are expressed in both the MDH superficial laminae and the Sp5O (Petralia et al., 1994), we questioned their role in windup at these two locations using in vivo single unit microelectrode recordings in Sp5O combined with microinjections of NMDA receptor agonists or antagonists in either Sp5O or MDH. WDR nociceptive neurons ( $n=55$, one per rat) were recorded from the ventrolateral part of the Sp5O (Dallel et al., 1990; Dallel et al., 1998; Dallel et 
al., 1999). Neurons were not spontaneously active. Most had receptive fields located within or around the oral cavity or nose (maxillary, $n=43$; ophthalmic, $n=1$; both, $n=11$ ). Sp5O WDR neurons responded to mechanical stimulation by increasing their firing rate as the intensity of the stimuli increased into the noxious range (Fig. 2A). The percutaneous electrical stimulation of Sp5O WDR neuron excitatory receptor fields induced two peaks of activation (Fig. 2B and C).

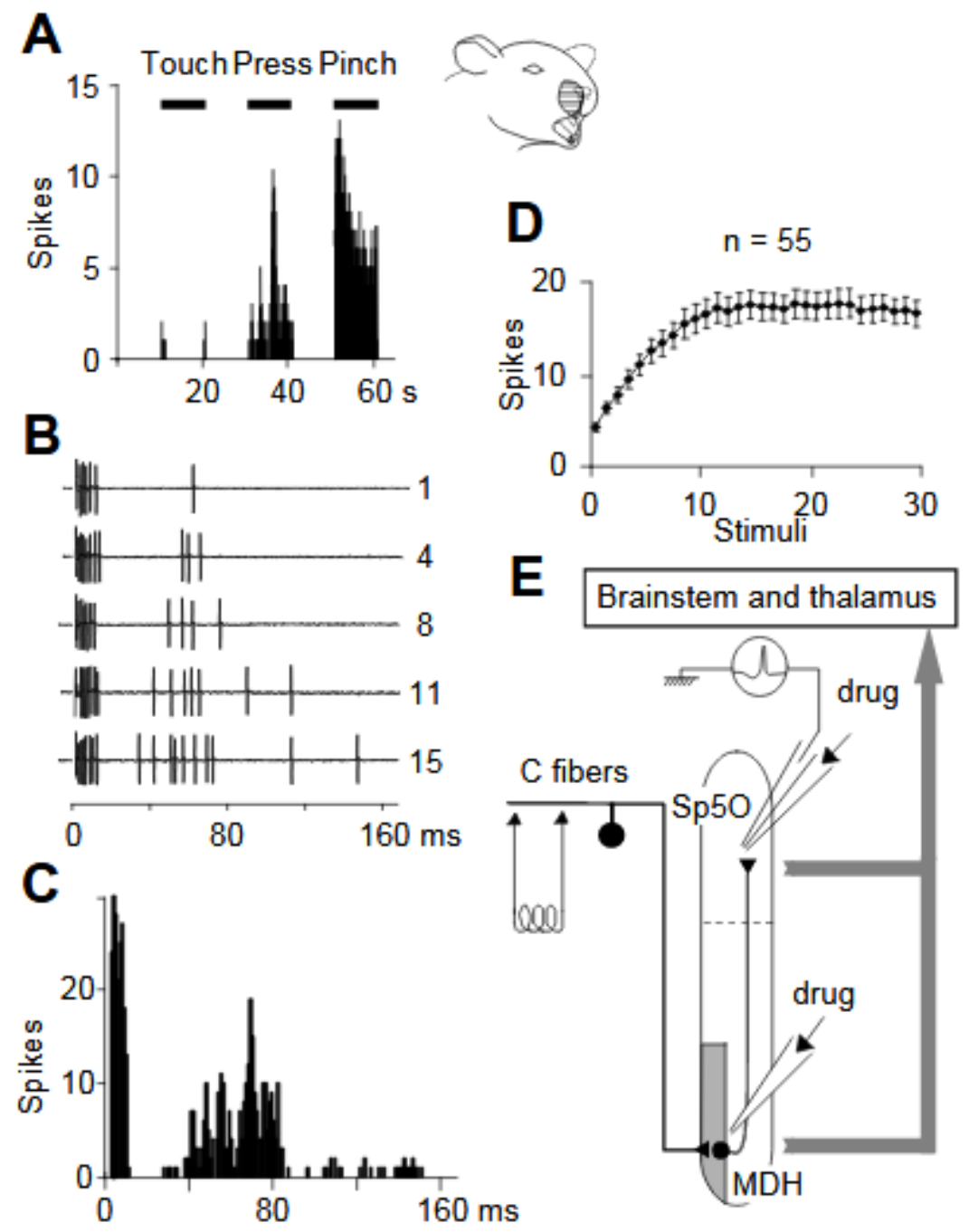

Fig.2. Sp5O wide dynamic range nociceptive neurons display windup in response to repeated stimulation of $C$-fibres. (A) Responses of a Sp5O neuron to mechanical stimulation applied to its receptive field (shown in grey). (B) Examples of consecutive oscilloscope single sweep recordings showing the $A$-fibre and $C$-fibre evoked responses to repetitive percutaneous suprathreshold electrical stimulation $(0.66 \mathrm{~Hz})$. (C) Post-stimulus time histogram showing the cumulated response to 30 trials in a single neuron. (D) Evolution over time of the mean number $(+/-S E M)$ of $C$-fibre latency spikes triggered by repetitive stimulation. $(\boldsymbol{E})$ Schematic diagram illustrating the processing of trigeminal C-fibre input to the Sp5O. 
The first peak was obtained at a mean threshold of $0.30+/-0.05 \mathrm{~mA}$ and a mean latency of 2.51+/$0.11 \mathrm{~ms}$. The second peak occurred at a mean threshold of 7.49+/-0.61 mA and at mean latency of 81.18+/-3.4 9ms. According to Gasser \& Erlanger (1927) and Burgess \& Perl (1973), such values correspond to A-fibres and C-fibres, respectively. In all neurons, windup could be observed in the latency range of C-fibres (Fig. 2B and D).

\section{NMDA receptors within the Sp5O are involved in windup}

We first investigated the role of NMDA receptor activity in the Sp5O upon windup. Microinjections of NMDA receptor antagonists or agonists were performed near to the recorded Sp5O WDR neurons (Fig. 2E). On the one hand, microinjections of the NMDA receptor antagonist AP-5 (2.0 fmol) decreased Sp5O neuron windup by $24+/-6 \%$ at $40 \mathrm{~min}(\mathrm{P}<0.05)$, with return to control values within $75 \mathrm{~min}$. This showed that Sp5O WDR neuron windup depends on local NMDA receptors (Fig. 3A and B).
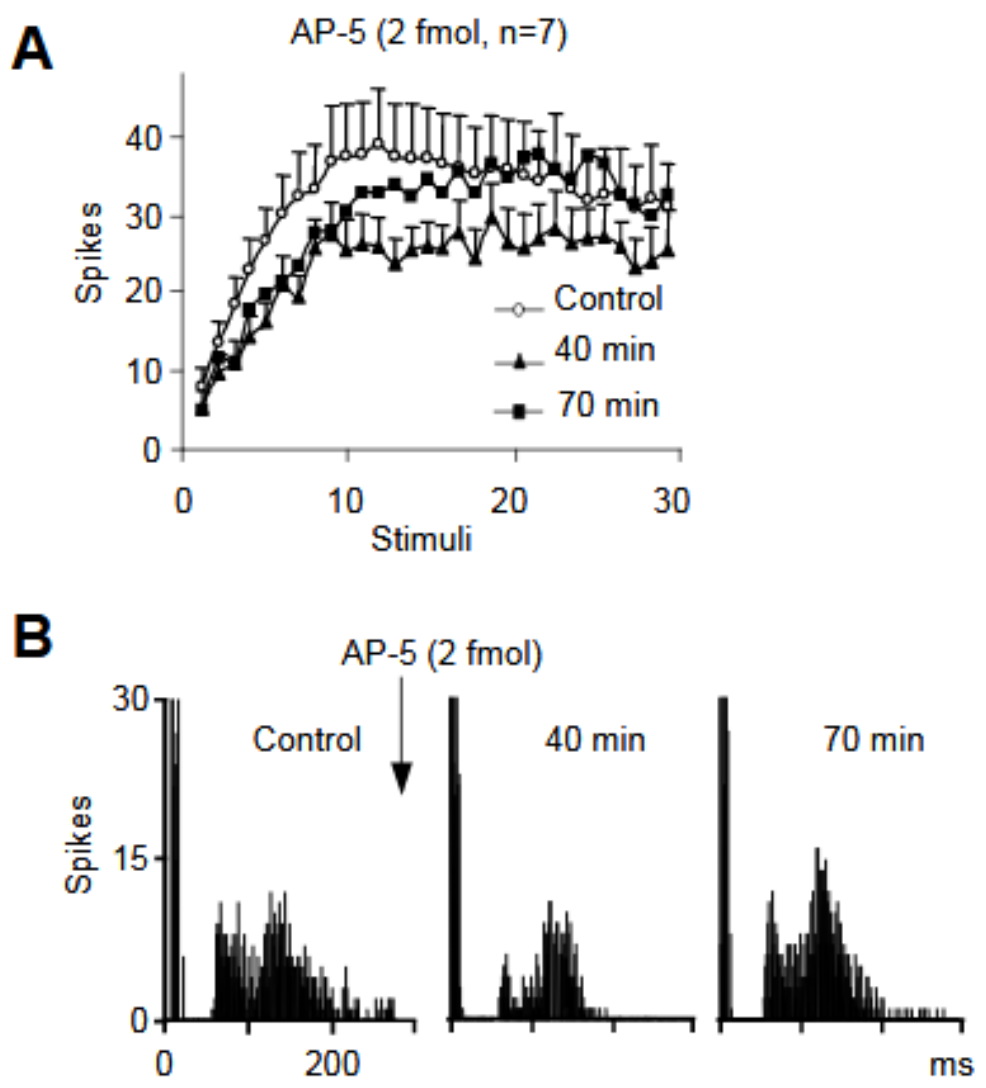

Fig.3. Sp5O WDR neuron windup depend on local NMDA receptors. (A) Microinjection of the $N M D A$ receptor antagonist AP-5 in the Sp5O reversibly decreased Sp5O neuron windup. For clarity, the error bars for the recovery traces are not shown. (B) Post-stimulus time histograms illustrating the time course of the effect of AP-5 upon cumulated responses in a single Sp5O neuron. 
The $\mathrm{C}$ response (the response to the first stimulus in the series) was reduced by AP-5 microinjections slightly, but not significantly, from $8.1+/-2.5$ to $5.3+/-2.4$ spikes $(n=7)$. In no case was A-fibre evoked activity altered significantly $(n=7)$. On the other hand, single microinjections of NMDA (1 nmol) triggered immediate short-lasting bursts of action potentials (1746+/-46 spikes for $56+/-12 \mathrm{~s})$ in all tested neurons $(\mathrm{n}=25)$ and increased windup in 12 out of 17 neurons, by $62+/-19 \%$ at $5 \mathrm{~min}(\mathrm{P}<0.001)$, with return to control values within $15 \mathrm{~min}$ (Fig. 4A and B).
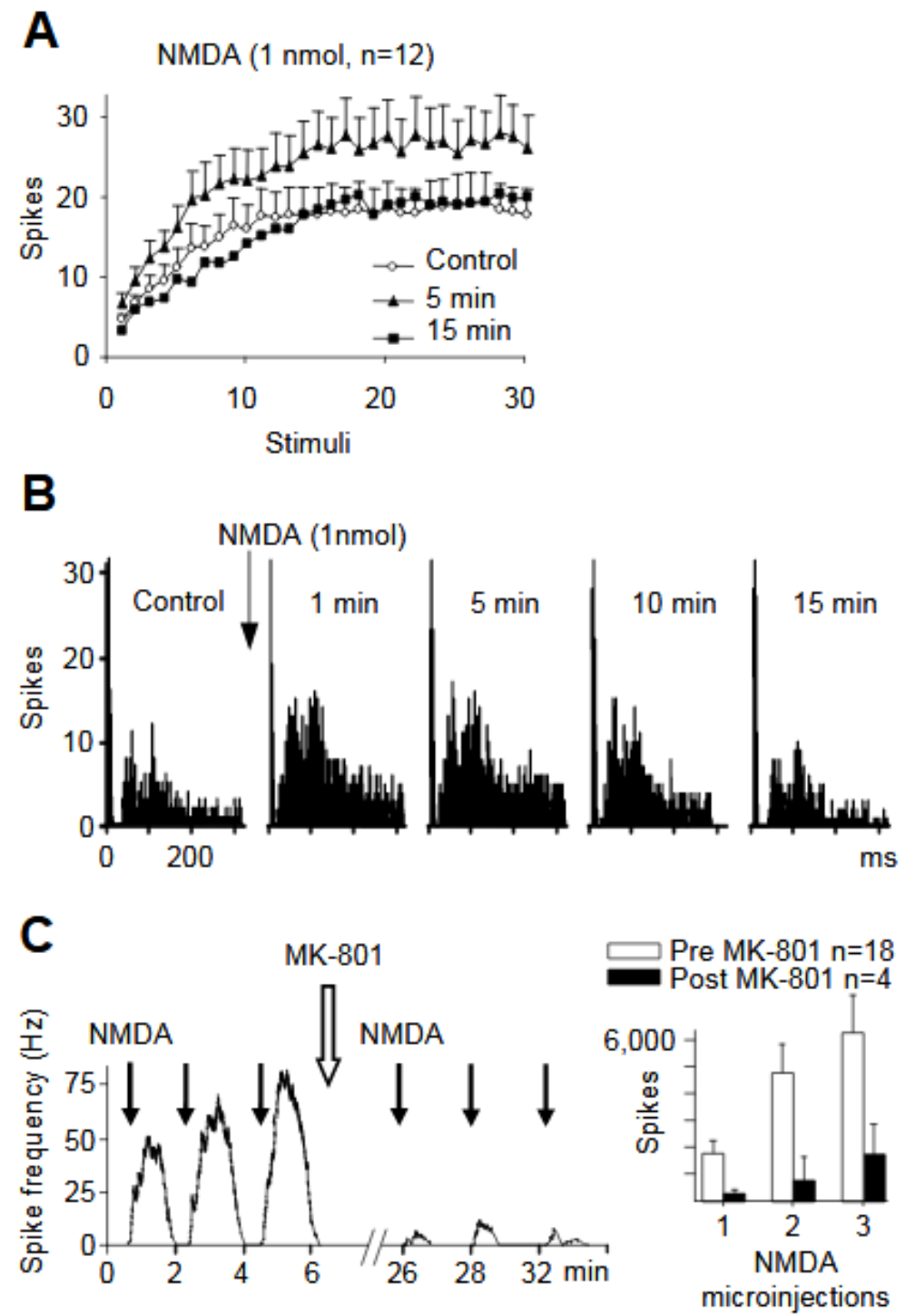

Fig. 4. Windup can be generated through activation of NMDA receptors within the Sp5O. (A) Microinjection of NMDA in the Sp5O reversibly increased Sp5O neuron windup. For clarity, the error bars for the recovery traces are not shown. (B) Post-stimulus time histograms illustrating the time course of the effect of NMDA upon cumulated responses in a single Sp5O neuron. (C) Low-frequency activation of NMDA receptors by repetitive microinjections of NMDA in the Sp5O mimicked windup, a response blocked by intravenous MK-801. Left, example in a single neuron; right, plot of mean values (+/-SEM) 
NMDA microinjections enhanced the $C$ response slightly, but not significantly, from $4.7+/-0.7$ to $6.1+/-1.3$ spikes $(n=12)$. NMDA microinjections did not change windup in the five remaining cells. Furthermore, low-frequency activation of NMDA receptors by repetitive microinjections of NMDA in the Sp5O resulted in a progressive increment in the amplitude of the response recorded as action potential discharge (Fig. 4C). This effect was blocked by intravenous injection of the NMDA receptor antagonist MK-801 (0.15 mg/kg, Fig. 4C). Microinjections of the vehicle alone had no effect upon spontaneous activity, or on windup $(n=4)$. Altogether, these results indicate that windup can be generated through activation of NMDA receptors within the Sp5O.
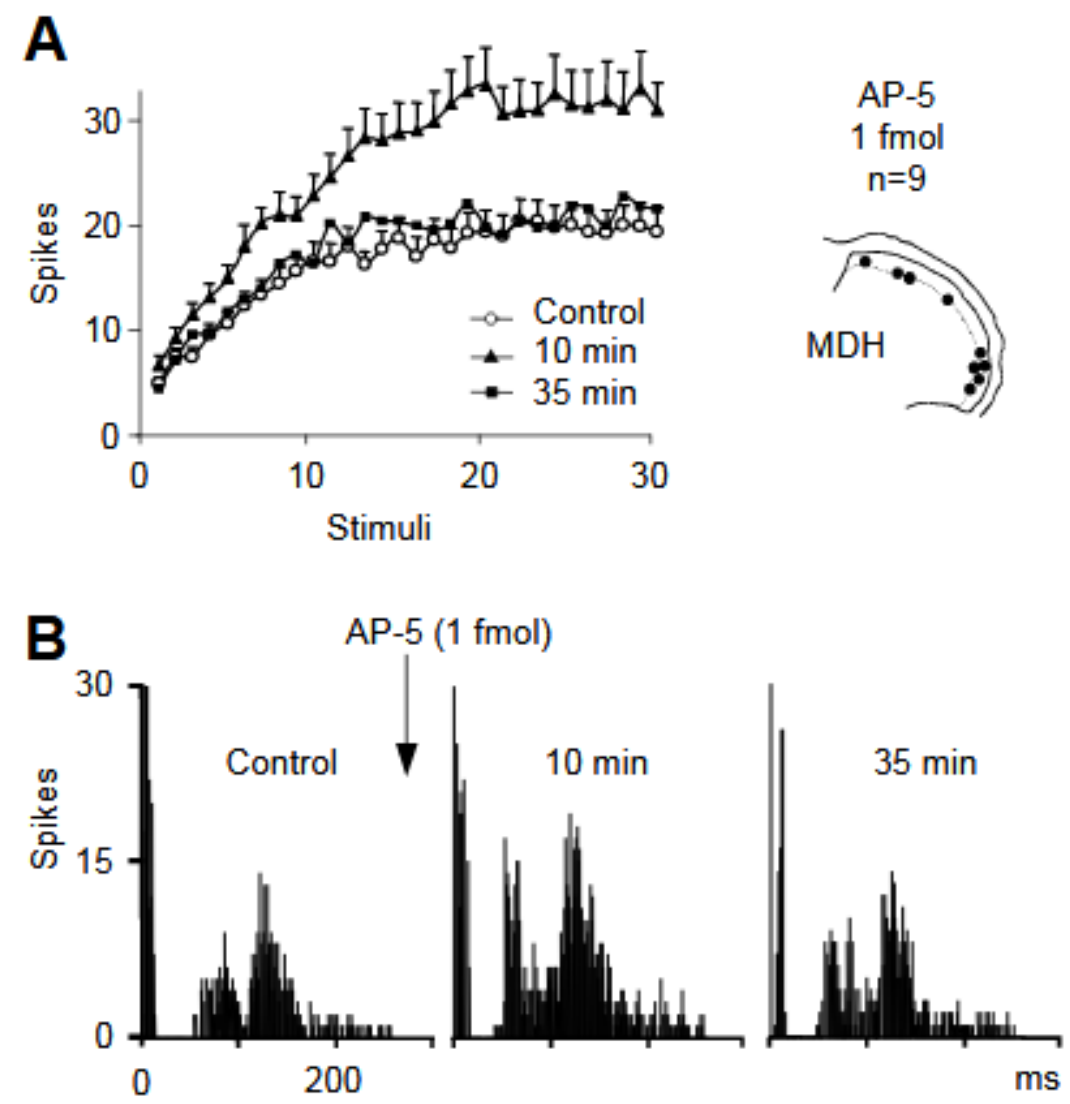

Fig.5. Activation of NMDA receptors by the segmental nociceptive input in the MDH superficial laminae restrains windup. (A) Microinjections of the NMDA receptor antagonist AP-5 in the superficial laminae of the $M D H$ reversibly increased $S p 5 O$ neuron windup. For clarity, the error bars of the recovery trace are not shown. The injection sites are mapped on the right. (B) Poststimulus time histograms illustrating the time course of the effect of AP-5 in the MDH upon cumulated responses in a single Sp5O neuron. 


\section{NMDA receptor activation in MDH superficial laminae restrains $\mathrm{Sp5O}$ neuron windup}

We then questioned the role of NMDA receptor activity in the superficial laminae of the MDH upon windup. Microinjections of NMDA receptor antagonists or agonists were performed within the MDH, while recording from Sp5O WDR neurons (Fig. 2E). Microinjections of the NMDA receptor antagonist AP-5 (1 fmol) within the superficial laminae of the MDH increased Sp5O neuron windup by $83+/-44 \%$ at $10 \mathrm{~min}(\mathrm{P}<0.05)$, with return to control values within $25 \mathrm{~min}$ (Fig. 5A and B). The $\mathrm{C}$ response was enhanced slightly, but not significantly, from $4.4+/-0.7$ to 6.0+/-0. 9spikes ( $\mathrm{n}=9)$. A-fibre evoked activity was not altered significantly $(\mathrm{n}=9)$. Microinjections of the vehicle alone had no effect upon spontaneous activity, or on windup ( $\mathrm{n}=4)$. These suggest that, while Sp5O WDR neurons windup their response to C- fibre stimulation, NMDA receptor activation in the superficial laminae of the dorsal horn restrains the amplification process. This inhibitory mechanism is activated by the segmental input and not tonic, as there was no effect of AP-5 on spontaneous firing $(n=9)$. Accordingly, microinjections of NMDA within the superficial laminae of the MDH dose-dependently decreased windup (Fig. 6A-C), and not A-fibre evoked activity. The $\mathrm{C}$ response was not modified. As shown by the results of microinjections of the largest dose of NMDA in different laminae of the MDH, the magnitude of this effect was closely related to a superficial location of the injection (Fig. 6D). Furthermore, microinjections of NMDA within the superficial laminae of the MDH at any dose tested (0.01-5 nmol) did not trigger any activity in Sp5O WDR neurons $(n=19)$, which suggests that NMDA receptors located in the superficial laminae of the $\mathrm{MDH}$ were not involved in the activation of the MDH-Sp5O circuit. 

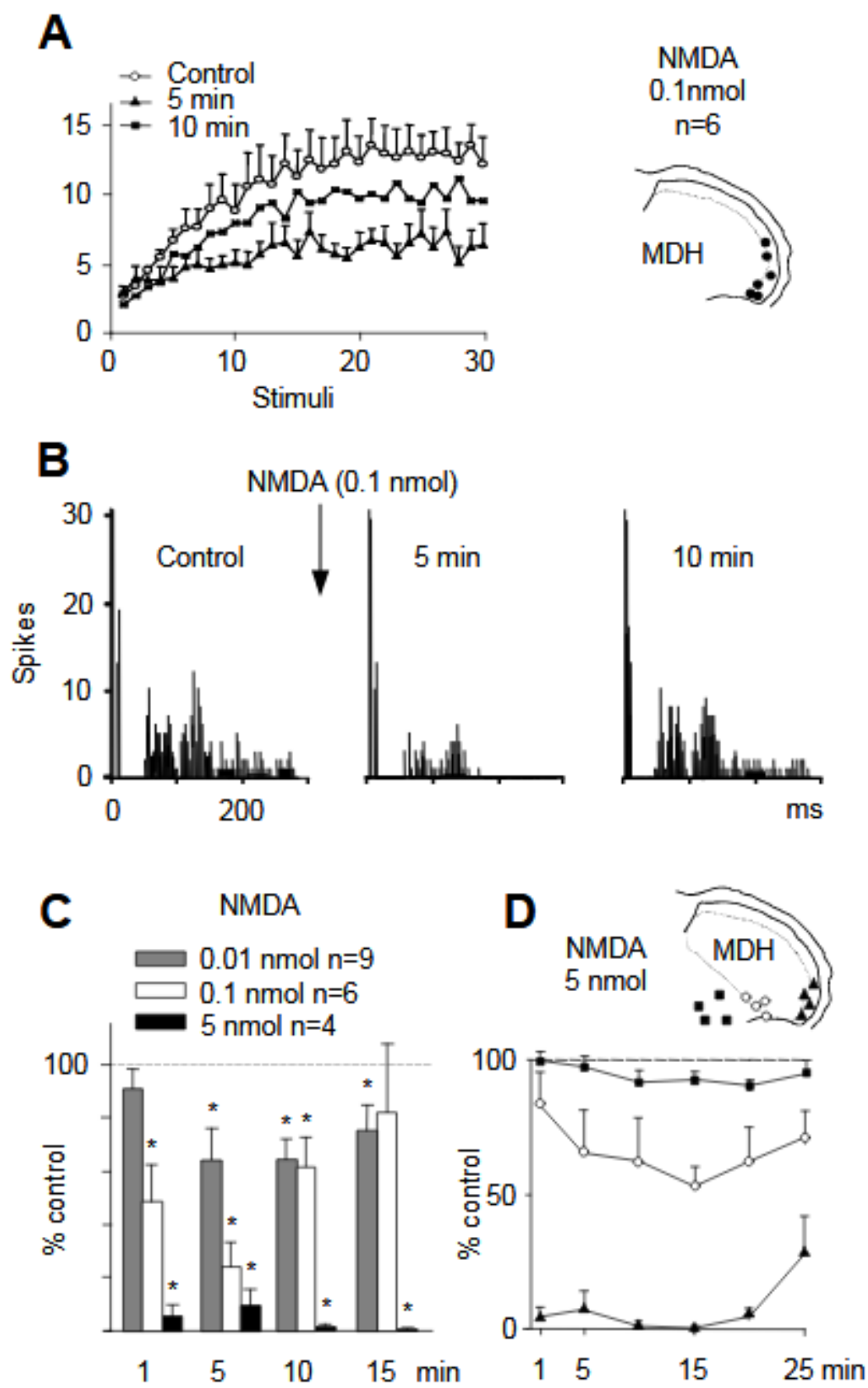

Fig.6. NMDA microinjection in the MDH superficial laminae restrains windup. (A) Microinjections of NMDA in the superficial laminae of the MDH decreased Sp5O neuron windup. For clarity, the error bars of the recovery trace are not shown. The injection sites are mapped on the right. (B) Poststimulus time histograms illustrating the time course of the effect of $N M D A$ in the $M D H$ upon cumulated responses in a single Sp5O neuron. (C) Dose-dependence of the inhibitory effect of NMDA in the MDH (* significantly different from control). (D) The inhibitory effect of NMDA depended on the injection site location. The sites of injection are illustrated on the top right. In $C$ and $D$, control refers to the cumulated number of $C$-fibre latency spikes triggered by 30 trials before drug injection. 


\section{Discussion}

Our results indicate that NMDA receptor function depends on their precise location in segmental nociceptive neural networks. We show that an important group of WDR nociceptive neurons receive nociceptive information indirectly, from a subpopulation of interneurons that lie in the superficial dorsal horn, where afferent nociceptive C-fibres terminate. At the end of this pathway, windup actually depends on NMDA receptor activation. Some NMDA receptors, thus, amplify pain information. In contrast, in the superficial dorsal horn, activation of NMDA receptors by the nociceptive input itself restrains windup. This suggests a new, inhibitory role for NMDA receptors in pain processing at the segmental level.

The trigeminal brainstem somatosensory system was used here to study where the synaptic NMDA mechanisms for windup operate. Although the MDH is generally considered as the essential brainstem relay of orofacial nociceptive information (Dubner \& Bennett, 1983), earlier findings have established that nociceptive neurons are in the Sp5O (Greenwood \& Sessle, 1976; Azerad et al., 1982; Dallel et al., 1990). The properties of Sp5O WDR neurons clearly resemble those of WDR neurons in lamina Vof the spinal dorsal horn. First, they respond to mechanical, thermal, chemical and electrical cutaneous (or mucosal) noxious stimuli as well as to nonnoxious stimuli (Raboisson et al., 1995). Second, they can be activated by stimulation of A-fibres as well as C-fibres, and encode both non-noxious and noxious stimuli (Dallel et al., 1999). The long latency responses that were recorded in the present work were due to activation of C-fibres as they could be evoked by high intensity stimulations only and exhibited windup during low frequency $(0.66 \mathrm{~Hz})$ suprathreshold electrical stimulation (Mendell, 1966; Wagman \& Price, 1969; Urban \& Randic, 1984; Woolf et al., 1988; Yoshimura \& Jessell, 1989; Thompson et al., 1994). Furthermore, in a previous work, Sp5O neuron long latency responses were also found to be depressed by intravenous morphine in a naloxone-dependent way (Dallel et al., 1998). They were also strongly and quickly reduced by intracutaneous injection of capsaicin $(0.1 \%)$, with little effect on the short latency responses (Dallel et al., 1999).

Common structural features are shared by the $\mathrm{Sp} 5 \mathrm{O}$ and lamina $\mathrm{V}$ of the spinal dorsal horn. First, cutaneous C-fibres terminate in the superficial laminae of the dorsal horn only and do not contact directly WDR neurons located either in lamina Vof the dorsal horn or in Sp5O (Light \& Perl, 1979a; Light \& Perl, 1979b; Ralston, III \& Ralston, 1982; Sugiura et al., 1986; Ambalavanar \& Morris, 1992). Second, opioid receptors (Atweh \& Kuhar, 1977; Arvidsson et al., 1995; Ding et 
al., 1996) as well as substance P, a marker for peptidergic C-fibres (Sugimoto et al., 1997) are not seen in significant amount within these regions. Finally, while morphine has no direct effect upon Sp5O or lamina V WDR neuron activity, it can inhibit their response to noxious stimuli when injected in the corresponding superficial laminae of the dorsal horn (Duggan et al., 1977; Fleetwood-Walker et al., 1988; Dallel et al., 1998). The present anatomical findings further validate the trigeminal model for studying segmental nociceptive integration. As previously reported, the distribution of fos-like immunoreactive neurons in laminae I-II induced by low doses of capsaicin matched the known distribution of nociceptive C-fibre terminals (Hunt et al., 1987; Strassman \& Vos, 1993). The effects of capsaicin on peripheral afferents vary with doses: low capsaicin concentrations, such as $0.1 \%$, affect unmyelinated fibres selectively, while higher concentrations affect both A-fibres and C-fibres (Holzer, 1991). It is therefore likely that, in this study, Fos expression resulted from $\mathrm{C}$-input activation. The retrograde labelling confirmed the existence of ipsilateral connections from the $\mathrm{MDH}$ to the Sp5O. In the present study, however, the total amount of cells counted in the MDH was much larger than in our previous work (Voisin et al ., 2002). This may be explained by the use of a pure retrograde tracer ( uorogold) instead of a dual antero/retrograde tracer (tetramethylrhodamine-dextran), combined to the larger size of the injection sites. The general lamina specific distribution of labelling was nevertheless similar in the two studies, although a consistent number of retrogradely labelled cells was found here in the outer lamina II (approximately $2 \%$ of the total number of retrogradely labelled neurons). The double-labelling study showed that interneurons located in the superficial laminae of the MDH convey trigemina nociceptive C-fibre input to WDR Sp5O neurons. This is in good agreement with results of recent work showing that $\mathrm{Sp5O}$ neurons receive their nociceptive C-input indirectly via the MDH (Dallel et al., 1998; Park et al., 2001; Chiang et al., 2002). The MDH$\mathrm{Sp5O}$ organization is thus similar to that found in the spinal dorsal horn, where the important group of WDR neurons, which lie in the deep dorsal horn of the spinal cord, receive a strong polysynaptic C-fibre input from the superficial laminae (Ritz \& Greenspan, 1985; Light \&Kavookjian, 1988; Li et al., 1999; Nakatsuka et al., 2002).

Our electrophysiological data indicate that, at the end of this circuit, i.e. in the Sp5O, WDR neuron windup depends on NMDA receptors. This is consistent with previous in vitro and in vivo studies of the deep dorsal horn/trigeminal systems supporting the involvement of NMDA receptors in windup (Davies \& Lodge, 1987; Dickenson \& Sullivan, 1990; Parada et al., 1997; 
Luccarini et al., 2001; Woda et al., 2001). At the cellular level, temporal summation of slow excitatory postsynaptic potentials may lead to a cumulative depolarization (Sivilotti et al., 1993). Additional NMDA receptor current on removal of the $\mathrm{Mg}^{2+}$ block of the channels would further promote windup (Woolf \& Salter, 2000). It is unlikely, however, that glutamate released from Cfibre terminals directly reaches postsynaptic NMDA receptors on WDR neurons in Sp5O, as well as in lamina V of the dorsal horn (Light \& Perl, 1979b; Ralston, III \& Ralston, 1982; Sugiura et al., 1986; Dallel et al., 1998). It is tempting to speculate that interneurons that transmit the nociceptive input from the superficial laminae provide the glutamatergic input to deep dorsal horn and Sp5O WDR nociceptive neurons. In summary, windup depends upon NMDA receptor activation at the end of the pathway which allows WDR neuron activation by C-fibres.

Our most intriguing finding, however, is that while amplification of the C-fibre input is in progress during windup, it remains under the control of an inhibitory mechanism. This mechanism depends on NMDA receptors located in the superficial laminae of the dorsal horn. This suggests a new, inhibitory role for NMDA receptors in pain processing at the segmental level. Such a mechanism is not tonic and is activated by the incoming nociceptive input itself. Indeed, it is unlikely to be triggered by activation of myelinated, large diameter fibres, as the inhibition could not be evoked from laminae III-IVof the dorsal horn where most A $\beta$-fibres terminate (Light \& Perl, 1979a; Willis \& Coggeshall, 1991). Furthermore, in the dorsal horn, NMDA receptors contribute to neurotransmission of C-fibre dependent inputs, not innocuous stimuli (Morris, 1989; King \& Lopez-Garcia, 1993). The inhibitory mechanism also differs from heterotopic modulation by diffuse noxious inhibitory control (Le Bars et al., 1979), as it was evoked from the receptor field of the recorded neuron. A variety of inhibitory interneurons containing GABA, glycine or enkephalin have been shown to be present in the superficial dorsal horn (Hunt et al., 1981; Todd, 1990) and they may be involved in the NMDA-dependent inhibition of windup. Interestingly, terminals from unmyelinated primary afferent fibres synaptically contact GABA containing neurons (Bernardi et al., 1995) and some of these develop Fos immunoreactivity after noxious stimulation (Todd et al., 1994). Furthermore, NMDA receptor antagonists attenuate Fos expression in spinal dorsal horn GABAergic neurons after intradermal injection of capsaicin (Zou et al., 2001). 
Functionally, the NMDA-dependent inhibition of windup, by working in concert with NMDA receptors that amplify pain information, provides a means of tuning the gain in nociception at the segmental level (Woolf \& Salter, 2000). Windup and central sensitization are clearly not equivalent (Woolf, 1996), as windup amplifies the pain message for a few minutes only. The NMDA-dependent inhibition of windup, however, might prevent further activation of the intracellular ignalling cascades involved in the development of central sensitization under sustained nociceptive C-fibre barrage (Woolf \& Salter, 2000). We may thus speculate that under pathological conditions, dysfunction of the NMDA-dependent inhibition of windup could contribute to central sensitization of pain systems.

\section{Acknowledgements}

We thank C.W. Bourque, J.P. Lund, F. Nagy and V.S. Fénelon for providing comments on an early draft of this manuscript. We also thank M. Chalus for technical assistance and D. Faulks for English editing. This work was supported by funding from the European Community (BIO 4.98.0076), and INSERM, Fondation pour la Recherche Médicale, Direction Générale des Armées (01.34.012.00470.75.01), Université d'Auvergne (France).

\section{Abbreviations}

MDH: medullary dorsal horn

NMDA: N-methyl-D-aspartate

Sp5O: subnucleus oralis of the spinal trigeminal nucleus

WDR: wide dynamic range

\section{References}

Akaoka, H., Saunier, C.F., Chergui, K., Charlety, P., Buda, M. \& Chouvet, G. (1992) Combining in vivo volume-controlled pressure microejection with extracellular unit recording. J. Neurosci. Meth.,42, 119-128. 
Ambalavanar, R. \& Morris, R. (1992) The distribution of binding by isolectin I-B4 from Griffonia simplicifolia in the trigeminal ganglion and brainstem trigeminal nuclei in the rat. Neuroscience, 47, 421-429.

Arvidsson, U., Riedl, M., Chakrabarti, S., Lee, J.H., Nakano, A.H., Dado, R.J., Loh, H.H., Law, P.Y., Wessendorf, M.W. \& Elde, R. (1995) Distribution and targeting of a $\mu$-opioid receptor (MOR1) in brain and spinal cord. J. Neurosci., 15, 3328-3341.

Atweh, S.F. \& Kuhar, M.J. (1977) Autoradiographic localization of opiate receptors in rat brain. I. Spinal cord and lower medulla. Brain Res., 124 ,53-67.

Azerad, J., Woda, A. \& Albe-Fessard, D. (1982) Physiological properties of neurons in different parts of the trigeminal sensory complex. Brain Res., 246, 7-21.

Baranauskas, G. \& Nistri, A. (1998) Sensitization of pain pathways in the spinal cord: Cellular mechanisms. Prog. Neurobiol., 54, 349-365.

Bernardi, P.S., Valtschanoff, J.G., Weinberg, R.J., Schmidt, H.H. \& Rustioni, A. (1995) Synaptic interactions between primary afferent terminals and GABA and nitric oxide-synthesizing neurons in superficial laminae of the rat spinal cord. J. Neurosci., 15, 1363-1371.

Burgess, P.R. \& Perl, E.R. (1973) Cutaneous mechanoreceptors and nociceptors. In Iggo, A., (E), Handbook of Sensory Physiology,Vol.2. Somatosensory System. Springer, Berlin, pp. 29-78.

Caterina, M.J. \& Julius, D. (2001) The vanilloid receptor: a molecular gateway to the pain pathway. Ann. Rev. Neurosci., 24, 487-517.

Chapman, V., Haley, J.E. \& Dickenson, A.H. (1994) Electrophysiologic analysis of preemptive effects of spinal opioids on N-methyl-D-aspartate receptor-mediated events. Anesthesiology, 81, 1429-1435.

Chiang, C.Y., Hu, B., Hu, J.W., Dostrovsky, J.O. \& Sessle, B.J. (2002) Central sensitization of nociceptive neurons in trigeminal subnucleus oralis depends on integrity of subnucleus caudalis. J. Neurophysiol., 88, 256-264.

Dallel, R., Duale, C., Luccarini, P. \& Molat, J.L. (1999) Stimulus-functon, wind-up and modulation by diffuse noxious inhibitory controls of responses of convergent neurons of the spinal trigeminal nucleus oralis . Eur. J. Neurosci., 11, 31-40. 
Dallel, R., Duale, C. \& Molat, J.L. (1998) Morphine administered in the substantia gelatinosa of the spinal trigeminal nucleus caudalis inhibits nociceptive activities in the spinal trigeminal nucleus oralis. J. Neurosci., 18, 3529-3536.

Dallel, R., Raboisson, P., Auroy, P. \& Woda, A. (1988) The rostral part of the trigeminal sensory complex is involved in orofacial nociception .Brain Res., 448, 7-19.

Dallel, R., Raboisson, P., Woda, A. \& Sessle, B.J. (1990) Properties of nociceptive and nonnociceptive neurons in trigeminal subnucleus oralis of the rat. Brain Res.,21, 95-106.

Davies, S.N. \& Lodge, D. (1987) Evidence for involvement of N-methylaspartate receptors in 'wind- up' of class 2 neurones in the dorsal horn of the rat. Brain Res., 424, 402-406.

Derjean, D., Bertrand, S., Le Masson, G., Landry, M., Morisset, V. \& Nagy, F. (2003) Dynamic balance of metabotropic inputs causes dorsal horn neurons to switch functional states. Nature Neurosci., 6, 274-281.

Dickenson, A.H. \& Sullivan, A.F. (1990) Differential effects of excitatory amino acid antagonists on dorsal horn nociceptive neurones in the rat. Brain Res., 506, 31-39.

Ding, Y.Q., Kaneko, T., Nomura, S. \& Mizuno, N. (1996) Immunohistochemical localization of $\mu$-opioid receptors in the central nervous system of the rat. J. Comp. Neurol., 367, 375-402.

Dubner, R. \& Bennett, G.J. (1983) Spinal and trigeminal mechanisms of nociception. Ann. Rev. Neurosci., 6, 381-418.

Duggan, A.W., Hall, J.G. \& Headley, P.M. (1977) Suppression of transmission of nociceptive impulses by morphine: selective effects of morphine administered in the region of the substantia gelatinosa. Br. J. Pharmacol., 61, 65-76.

Fleetwood-Walker, S.M., Hope, P.J., Mitchell, R., El-Yassir, N. \& Molony, V. (1988) The influence of opioid receptor subtypes on the processing of nociceptive inputs in the spinal dorsal horn of the cat. Brain Res., 451, 213-226.

Gasser, H.S. \& Erlanger, J. (1927) The role played by the sizes of the constituent fibers of a nerve trunk in determining the form of its action potential wave. Am. J. Physiol., 80, 522-547. 
Greenwood, L.F. \& Sessle, B.J. (1976) Inputs to trigeminal brain stem neurones from facial, oral, tooth pulp and pharyngolaryngeal tissues. II. Role of trigeminal nucleus caudalis in modulating responses to innocuous and noxious stimuli. Brain Res., 117, 227-238.

Herrero, J.F., Laird, J.M.A. \& Lopez-Garcia, J.A. (2000) Wind-up spinal cord neurones and pain sensation: much ado about something. Prog. Neurobiol., 61, 169-203.

Holzer, P. (1991) Capsaicin: Cellular targets, mechanisms of action, and selectivity for thin sensory neurons. Pharmacol. Rev., 43, 143-201.

Hunt, S.P., Kelly, J.S., Emson, P.C., Kimmel, J.R., Miller, R.J. \& Wu, J.Y. (1981) An immunohistochemical study of neuronal populations containing neuropeptides or $\gamma$ aminobutyrate within the superficial layers of the rat dorsal horn. Neuroscience, 6, 1883-1898.

Hunt, S.P., Pini, A. \& Evan, G. (1987) Induction of c-fos-like protein in spinal cord neurons following sensory stimulation. Nature, 328, 632-634.

Jeftinija, S. \& Urban, L. (1994) Repetitive stimulation induced potentiation of excitatory transmission in the rat dorsal horn: an in vitro study. J. Neurophysiol., 71, 216-228.

King, A.E. \& Lopez-Garcia, J.A. (1993) Excitatory amino acid receptor-mediated neurotransmission from cutaneous afferents in rat dorsal horn in vitro. J. Physiol. (Lond.), 472, 443-457.

Le Bars, D., Dickenson, A.H. \& Besson, J.M. (1979) Diffuse noxious inhibitory controls (DNICC). I. Effects on dorsal horn convergent neurones in the rat. Pain, 6, 283-304.

Li, Y.Q., Li, H., Kaneko, T. \& Mizuno, N. (1999) Substantia gelatinosa neurons in the medullary dorsal horn: An intracellular labeling study in the rat. J. Comp. Neurol., 411, 399-412.

Light, A.R. \& Kavookjian, A.M. (1988) Morphology and ultrastructure of physiologically identified substantia gelatinosa (lamina II) neurons with axons that terminate in deeper dorsal horn laminae (III-V). J. Comp. Neurol., 267, 172-189.

Light, A.R. \& Perl, E.R. (1979a) Reexamination of the dorsal root projection to the spinal dorsal horn including observations on the differential termination of coarse and fine fibers. J. Comp. Neurol., 186, 117-132. 
Light, A.R. \& Perl, E.R. (1979b) Spinal termination of functionally identified primary afferent neurons with slowly conducting myelinated fibers. J. Comp. Neurol., 186, 133-150.

Luccarini, P., Sessle, B.J. \& Woda, A. (2001) Superficial and deep convergent nociceptive neurons are differentially affected by N-methyl-D-aspartate applied on the brainstem surface of the rat medullary dorsal horn. Neuroscience, 107, 311-316.

Mendell, L.M. (1966) Physiological properties of unmyelinated fiber projection to the spinal cord. Exp. Neurol., 16, 316-332.

Mendell, L.M. \& Wall, P.D. (1965) Responses of dorsal cord cell to peripheral cutaneous unmyelinated fibres. Nature, 206, 97-99.

Morisset, V. \& Nagy, F. (1999) Ionic basis for plateau potentials in deep dorsalhorn neurons of the rat spinal cord. J. Neurosci., 19, 7309-7316.

Morisset, V. \& Nagy, F. (2000) Plateau potential-dependent windup of the response to primary afferent stimuli in rat dorsal horn neurons. Eur. J. Neurosci., 12, 3087-3095.

Morris, R. (1989) Responses of spinal dorsal horn neurones evoked by myelinated primary afferent stimulation are blocked by excitatory amino acid antagonists acting at kainate/quisqualate receptors. Neurosci. Lett., 105, 79-85.

Nakatsuka, T., Furue, H., Yoshimura, M. \& Gu, J.G. (2002) Activation of central terminal vanilloid receptor-1 receptors and alpha beta-methylene-ATP-sensitive P2X receptors reveals a converged synaptic activity onto the deep dorsal horn neurons of the spinal cord. J. Neurosci., 22, 1228-1237.

Parada, C.A., Luccarini, P. \& Woda, A. (1997) Effect of an NMDA receptor antagonist on the wind-up of neurons in the trigeminal oralis subnucleus. Brain Res., 761, 313-320.

Park, S.J., Chiang, C.Y., Hu, J.W. \& Sessle, B.J. (2001) Neuroplasticity induced by tooth pulp stimulation in trigeminal subnucleus oralis involves NMDA receptor mechanisms. $J$. Neurophysiol., 85, 1836-1846.

Paxinos, G. \& Watson, C. (1997) The Rat Brain in Stereotaxic Coordinates. Academic Press, London. 
Petralia, R.S., Yokotani, N. \& Wenthold, R.J. (1994) Light and electron microscope distribution of the NMDA receptor subunit NMDAR1 in the rat nervous system using a selective anti-peptide antibody. J. Neurosci., 14, 667-696.

Raboisson, P., Dallel, R., Clavelou, P., Sessle, B.J. \& Woda, A. (1995) Effects of subcutaneous formalin on the activity of trigeminal brain stem nociceptive neurones in the rat. J. Neurophysiol., 73, 496-505.

Ralston, H.J. III \& Ralston, D.D. (1982) The distribution of dorsal root axons to laminae IV, V, and VI of the Macaque spinal cord: a quantitative electron microscopic study. J. Comp. Neurol., 212, 435-448.

Ritz, L.A. \& Greenspan, J.D. (1985) Morphological features of lamina V neurons receiving nociceptive input in cat sacrocaudal spinal cord. J. Comp. Neurol., 238, 440-452.

Russo, R.E. \& Hounsgaard, J. (1999) Dynamics of intrinsic electrophysiological properties in spinal cord neurones. Prog. Biophys. Mol. Biol., 72, 329-365.

Schouenborg, J. \& Sjölund, B.H. (1983) Activity evoked by A- and C-afferent fibers in rat dorsal horn neurons and its relation to a flexion reflex. J. Neurophysiol., 50, 1108-1121.

Sessle, B.J. (2000) Acute and chronic craniofacial pain: Brainstem mechanisms of nociceptive transmission and neuroplasticity, and their clinical correlates. Crit. Rev. Oral Biol. Med., 11, 5791.

Sivilotti, L.G., Thompson, S.W.N. \& Woolf, C.J. (1993) Rate of rise of the cumulative depolarization evoked by receptive stimulation of small caliber afferents is a predictor of action potential windup in rat spinal neurons in vitro. J. Neurophysiol., 69, 1621-1631.

Strassman, A.M.\& Vos, B.P. (1993) Somatotopic and laminar organization of fos-like immunoreactivity in the medullary and upper cervical dorsal horn induced by noxious facial stimulation in the rat. J. Comp. Neurol., 331, 495-516.

Sugimoto, T., Fujiyoshi, Y., Xiao, C., He, Y.F. \& Ichikawa, H. (1997) Central projection of calcitonin gene-related peptide (CGRP)- and substance P (SP)-immunoreactive trigeminal primary neurons in the rat. J. Comp. Neurol., 378, 425-442. 
Sugiura, Y., Lee, C.L. \& Perl, E.R. (1986) Central projections of identified, unmyelinated (C) afferent fibers innervating mammalian skin. Science, 234,358-361.

Thompson, S.W., Dray, A. \& Urban, L. (1994) Injury-induced plasticity of spinal re-ex activity: NK1 neurokinin receptor activation and enhanced A- and C-fiber mediated responses in the rat spinal cord in vitro. J. Neurosci., 14, 3672-3687.

Todd, A.J. (1990) An electron microscope study of glycine-like immunoreactivity in laminae I-III of the spinal dorsal horn of the rat. Neuroscience, 39,387-394.

Todd, A.J., Spike, R.C., Brodbelt, A.R., Price, R.F. \& Shehab, S.A.S. (1994) Some inhibitory neurons in the spinal cord develop c-fos- immunoreactivity after noxious stimulation. Neuroscience, 63, 805-816.

Urban, L. \& Randic, M. (1984) Slow excitatory transmission in rat dorsal horn: possible mediation by peptides. Brain Res., 290, 336-341.

Urban, L., Thompson, S.W.N. \& Dray, A. (1994) Modulation of spinal excitability: Cooperation between neurokinin and excitatory amino acid neurotransmitters. TINS, 17, 432-438.

Voisin, D.L., Domejean-Orliaguet, S., Chalus, M., Dallel, R. \& Woda, A. (2002) Ascending connections from the caudal part to the oral part of the spinal trigeminal nucleus in the rat. Neuroscience, 109, 183-193.

Wagman, I.H. \& Price, D.D. (1969) Responses of dorsal horn cells of M.mulatta to cutaneous and sural nerve A and C fiber stimuli. J. Neurophysiol., 32 , 803-817.

Willis, W.D. \& Coggeshall, R.E. (1991) Sensory Mechanisms of the Spinal Cord . Plenum Press, New York \& London.

Woda, A., Molat, J.L. \& Luccarini, P. (2001) Low doses of N-methyl-D-aspartate antagonists in superficial laminae of medulla oblongata facilitate wind-up of convergent neurones. Neuroscience, 107, 317-327.

Woolf, C.J. (1996) Windup and central sensitization are not equivalent. Pain, 66, 105-108.

Woolf, C.J., Bennett, G.J., Doherty, M., Dubner, R., Kidd, B., Koltzenburg, M., Lipton, R., Loeser, J.D., Payne, R. \& Torebjork, E. (1998) Towards a mechanism-based classification of pain. Pain, 77, 227-229. 
Woolf, C.J. \& Salter, M.W. (2000) Neuronal plasticity: Increasing the gain in pain. Science, 288, $1765-1768$.

Woolf, C.J., Thompson, W.N. \& King, A.E. (1988) Prolonged primary afferent induced alterations in dorsal horn neurones, an intracellular analysis in vivo and in vitro. J. Physiol. (Paris), 83, 255-266.

Yoshida, A., Dostrovsky, J.O., Sessle, B.J. \& Chiang, C.Y. (1991) Trigeminal projections to the nucleus submedius of the thalamus in the rat. J. Comp. Neurol., 307, 609-625.

Yoshimura, M. (1996) Slow synaptic transmission in the spinal dorsal horn. Prog. Brain Res., $113,443-462$.

Yoshimura, M. \& Jessell, T. (1989) Primary afferent-evoked synaptic responses and slow potential generation in rat substantia gelatinosa neurons in vitro. J. Neurophysiol., 62, 96-108.

Zou, X., Lin, Q. \& Willis, W.D. (2001) NMDA or non-NMDA receptor antagonists attenuate increased Fos expression in spinal dorsal horn GABAergic neurons after intradermal injection of capsaicin in rats . Neuroscience, 106, 171-182. 